\title{
OPEN Tree canopy arthropods have idiosyncratic responses to plant ecophysiological traits in a warm temperate forest complex
}

\begin{abstract}
Rudi C. Swart ${ }^{\bowtie}$, Michael J. Samways \& Francois Roets
Biodiversity studies on forest canopies often have narrow arthropod taxonomic focus, or refer to a single species of tree. In response, and to better understand the wide range of drivers of arthropod diversity in tree canopies, we conducted a large-scale, multi-taxon study which (a) included effect of immediate surroundings of an individual tree on plant physiological features, and (b), how these features affect compositional and functional arthropod diversity, in a warm, southern Afro-temperate forest. We found that tree species differed significantly in plant physiological features and arthropod diversity patterns. Surprisingly, we found negative correlation between surrounding canopy cover, and both foliar carbon and arthropod diversity in host trees, regardless of tree species. Subtle, tree intraspecific variation in physiological features correlated significantly with arthropod diversity measures, but direction and strength of correlations differed among tree species. These findings illustrate great complexity in how canopy arthropods respond to specific tree species, to immediate surroundings of host trees, and to tree physiological features. We conclude that in natural forests, loss of even one tree species, as well as homogenization of the crown layer and/or human-induced environmental change, could lead to profound and unpredictable canopy arthropod biodiversity responses, threatening forest integrity.
\end{abstract}

Trees and their associated arthropods contribute greatly to terrestrial biodiversity, though ecologists only recently have begun to decipher the complexities of their interactions ${ }^{1}$. This progress has been possible as arthropods in tree canopies are now more accessible, making way for greater insights into the complexities of tree-arthropod interactions, including canopy arthropod feeding guild partitioning ${ }^{2}$, incorporation of evolutionary histories of host tree species ${ }^{3}$, and effects of host-tree genetic diversity on arthropod diversity ${ }^{4}$. However, how arthropod diversity in these little-known yet important elevated communities respond to subtle changes in plant physiological features, many of which are human-induced, remains poorly studied. Also, due to the large numbers of arthropod species supported at canopy level, many studies often focus on one arthropod taxonomic group ${ }^{2,5}$ or on a single tree species ${ }^{6,7}$. As the multi-taxon approach provides deeper insight into ecological patterns and processes $^{8}$, much of our earlier understanding regarding tree-arthropod interactions only applies in narrow contexts. A larger scale, multi-taxon approach is required to understand the drivers of arthropod diversity in forest canopies.

Host specificity of arthropods in tree canopies is lower than previously suggested ${ }^{9}$. Nevertheless, host tree species identity is an important driver of arthropod diversity in forest canopies, determined largely by differences in plant physiological features such as leaf size and shape, chemical defences, turgor, and nitrogen content ${ }^{10}$. The impact of the immediate surroundings of a tree individual on arthropod diversity, and tree physiology, remains poorly studied, yet important ${ }^{11}$. When surrounded by dense canopies, a focal tree individual receives less direct sunlight, which decreases its photosynthetic capabilities and alters its nutritional value ${ }^{12}$. Changes in available nutrients also affect plant physiological features ${ }^{13}$. These various changes influence arthropod diversity at tree canopy level, yet are poorly understood ${ }^{14}$.

Effect of climate change on the interaction between trees and associated arthropods also requires consideration, especially the extent to which tree responses to changing conditions might spill over to higher trophic levels ${ }^{15}$. Our poor understanding of these interactions is concerning given that even a $1^{\circ} \mathrm{C}$ increase in global temperature may have profound effects on the interactions between trees and arthropods ${ }^{16}$. Decreased rainfall from 
a changing climate can increase water stress, reduce growth, and so disrupt plant-arthropod dynamics, but can also increase forest vigour and growth, and lead to higher water use efficiency and extended growing seasons ${ }^{16,17}$.

Precisely how changes in environmental factors influence plant physiological features and how arthropods respond to these changes is difficult to predict, as there may be differences between plant species, as well as between arthropod taxa. For example, some generalist herbivores benefit from severe drought conditions, while certain specialist herbivores benefit from moderate drought levels ${ }^{15}$. This means that when incorporating tree physiological features in canopy-arthropod studies, multiple tree species and arthropod guilds are required. Such studies can provide new insight into how future climate change will shape tree canopy-arthropod interactions, as it does for plant-pollinator interactions ${ }^{18}$.

Analysis of leaf physiological features might provide information on tree nutrient status and investment in defence compounds, while contributing to assessment of tree stress, such as moisture deficiency. Foliar N concentration, in particular, is an important determinant of herbivore arthropod diversity, distribution, and feeding behaviour ${ }^{19}$. Conversely, increased levels of foliar $\mathrm{C}$ often indicate plant investment in anti-herbivory structural defence compounds, phenols, and tannins ${ }^{20}$. Consequently, relative increases in foliar $\mathrm{C} / \mathrm{N}$ ratio often indicate more allocation to carbon-based defences against herbivores, with still-contested effects on higher trophic levels ${ }^{21}$. Plant investment in production of these compounds is determined by level of light exposure ${ }^{21}$, which can fluctuate with subtle changes in moisture availability and temperature ${ }^{22}$. Drought-stress, for example, can increase relative metabolic uptake of $\delta 13 \mathrm{C}^{23}$. In turn, variations in $\delta 15 \mathrm{~N}$ indicate differences in $\mathrm{N}$ sources, for example, whether derived from the soil or atmosphere, while also indicating plant stress or exposure to pollution ${ }^{24}$. Response of canopy-associated arthropod assemblages to changes in $\mathrm{N}$ and $\mathrm{C}$ isotopes can therefore provide valuable information on their responses to various stressors as predicted under future climate change.

Few studies have evaluated canopy arthropod diversity patterns while including surrounding plot characteristics, with some seminal work including canopy density effects ${ }^{25}$ and tree immediate surround ${ }^{11}$. However, we are unaware of any work on how plot characteristics affect physiological features among a mix of different tree species in an indigenous forest system, and in turn, affect tree-associated arthropod diversity. In this novel study, we ask: (1) How do tree identity and plot characteristics affect tree physiological features, and arthropod diversity within tree canopies, and (2) How does canopy arthropod diversity change in response to intraspecific variations in tree physiological features. We therefore focus on the importance of tree surrounds, and use proxies for tree drought stress, carbon-based defences and differences in nutrient resources, to describe the diversity and distribution of canopy arthropod diversity.

\section{Results}

In total, 20,645 arthropod individuals were sampled, comprising 1512 species (Supplementary table S1 online). Estimates of species richness of $2569.5( \pm 109.98)$ and 2679.2 were obtained for Chao 2 and Jacknife2 indexes respectively, indicating that we sampled just over $58 \%$ of estimated species richness (Supplementary Fig. S1 online). Predators were the most species-rich guild, totalling 768 species and $51.79 \%$ of all sampled species, followed by herbivores (321 spp.), detritivores (207 spp.), tourists (129 spp.), and ants (36 spp.). Predators were also the most abundant guild, with 7549 individuals, $36.57 \%$ of all sampled individuals. Herbivores comprised 5538 of individuals, $26.82 \%$ of all catches. These were followed by detritivores ( 4366 individuals $=21.15 \%$ of all catches), ants ( 1175 individuals $=5.69 \%$ of all catches $)$ and tourists ( 1153 individuals $=5.58 \%$ of all catches $)$.

Effect of tree identity and plot characteristics on tree physiological features. Except for foliar $\mathrm{C}$, which was negatively correlated with plot cover, and foliar $\delta 15 \mathrm{~N} / 14 \mathrm{~N}$ increasing with focal tree cover, all plant physiological features were influenced only by tree identity (Table 1). Foliar $\mathrm{N}$ was the highest in $O$. ventosa (Supplementary Fig. S2 online). There was large variance around medians for $\delta 15 \mathrm{~N} / 14 \mathrm{~N}$ between tree species, with few significant differences detected (Supplementary Fig. S3 online). Significantly higher leaf C was only detected in C. dentata (Supplementary Fig. S4 online), with C. capensis having lowest levels of foliar C. Three tree species, C. capensis, O. ventosa and P. latifolius, had significantly higher levels of foliar $\delta 13 \mathrm{C} / 12 \mathrm{C}$ compared to O. c. macrocarpa, P. tricuspidatus, P. trifoliatus and R. melanophloeos (Supplementary Fig. S5 online). Curtisia dentata showed intermediate levels of $\delta 13 \mathrm{C} / 12 \mathrm{C}$, and $O$. ventosa had the lowest $\mathrm{C} / \mathrm{N}$ ratio (Supplementary Fig. S6 online).

Effect of tree identity and plot characteristics on canopy arthropod diversity. Arthropod species density (richness per standardized sampling area) varied between a mean of 48.8 ( \pm 5.09 SE) and 79.27 $( \pm 8.92 \mathrm{SE})$, and abundance between $122.33( \pm 19.46 \mathrm{SE})$ and $212.27( \pm 29.82 \mathrm{SE})$ for the different tree species (Table 2). Focal tree species was an important explanatory variable for differences in arthropod abundance for all groups except the predators and ants (Table 3). However, there were no significant differences between particular tree species after post-hoc analyses for overall arthropods or herbivores. Detritivores were most abundant in canopies of C. capensis, C. dentata, O. c. macrocarpa, O. ventosa and P. latifolius, and least abundant in the canopy of $P$. trifoliatus (Supplementary Fig. S7 online), whereas more tourists were sampled from the canopy of $P$. trifoliatus compared to P. tricuspidatus (Supplementary Fig. S8 online). Plot canopy cover was the second most important factor explaining abundance of sampled arthropods on focal trees, with plot cover negatively correlating with abundances of overall arthropods, herbivores, predators, detritivores and tourists (Table 3). Ant abundance was positively correlated to tree species richness (Table 3 ).

Species density of overall arthropods, herbivores, predators, detritivores and tourists were significantly different between different tree species (Table 3). Highest overall and predator species density was in canopies of C. dentata (Supplementary Figs. S9-10 online). Also, C. dentata hosted significantly more herbivore species than P. trifoliatus and R. melanophloeos (Supplementary Fig. S11 online), and had comparatively high numbers of 


\begin{tabular}{|c|c|c|c|c|c|}
\hline Physiological variable & Variable & num. df & $\mathbf{F}$ & $\operatorname{Pr}(>\mathrm{F})$ & Sig \\
\hline \multirow{5}{*}{$\mathrm{N}$} & Focal tree species & 7 & 21.38 & 0.000 & $* * *$ \\
\hline & \begin{tabular}{|l|} 
Focal tree cover \\
\end{tabular} & 1 & 0.43 & 0.51 & ns \\
\hline & Host same-species cover & 1 & 0.07 & 0.79 & ns \\
\hline & \begin{tabular}{|l|} 
Plot richness \\
\end{tabular} & 1 & 0.15 & 0.70 & ns \\
\hline & Plot cover & 1 & 1.33 & 0.25 & ns \\
\hline \multirow{5}{*}{$\delta 15 \mathrm{~N} / 14 \mathrm{~N}$} & Focal tree species & 7 & 6.08 & 0.000 & $* * *$ \\
\hline & \begin{tabular}{|l} 
Focal tree cover \\
\end{tabular} & 1 & 7.05 & 0.009 & $* *$ \\
\hline & \begin{tabular}{|l|} 
Host same-species cover \\
\end{tabular} & 1 & 0.50 & 0.48 & ns \\
\hline & \begin{tabular}{|l|} 
Plot richness \\
\end{tabular} & 1 & 0.12 & 0.73 & ns \\
\hline & Plot cover & 1 & 2.24 & 0.14 & ns \\
\hline \multirow{5}{*}{$\mathrm{C}$} & Focal tree species & 7 & 37.06 & 0.000 & $* * *$ \\
\hline & Focal tree cover & 1 & 1.99 & 0.16 & ns \\
\hline & Host same-species cover & 1 & 0.75 & 0.39 & ns \\
\hline & \begin{tabular}{|l|} 
Plot richness \\
\end{tabular} & 1 & 0.45 & 0.51 & ns \\
\hline & Plot cover & 1 & 5.48 & 0.02 & * \\
\hline \multirow{5}{*}{$\delta 13 \mathrm{C} / 12 \mathrm{C}$} & Focal tree species & 7 & 13.47 & 0.000 & $* * *$ \\
\hline & \begin{tabular}{|l|} 
Focal tree cover \\
\end{tabular} & 1 & 0.33 & 0.57 & ns \\
\hline & Host same-species cover & 1 & 0.00 & 0.97 & ns \\
\hline & \begin{tabular}{|l|} 
Plot richness \\
\end{tabular} & 1 & 1.24 & 0.27 & ns \\
\hline & Plot cover & 1 & 2.20 & 0.14 & ns \\
\hline \multirow{5}{*}{$\mathrm{C} / \mathrm{N}$} & Focal tree species & 7 & 27.42 & 0.000 & $* * *$ \\
\hline & Focal tree cover & 1 & 0.05 & 0.83 & ns \\
\hline & Host same-species cover & 1 & 0.33 & 0.57 & ns \\
\hline & \begin{tabular}{|l|} 
Plot richness \\
\end{tabular} & 1 & 0.83 & 0.36 & ns \\
\hline & Plot cover & 1 & 1.73 & 0.19 & ns \\
\hline
\end{tabular}

Table 1. Results of the linear mixed models indicating F-values for each of the model variables for the respective plant physiological variables, including the significance for each variable. '. $P<0.01$, '*' $P<0.05$, '**' $P<0.01$, '***) $P<0.001$.

\begin{tabular}{|l|c|c|c|c|c|c|c|c|}
\hline $\begin{array}{l}\text { Diversity } \\
\text { indices }\end{array}$ & C. capensis & C. dentata & $\begin{array}{l}\text { O. } \text {. } \\
\text { macrocarpa }\end{array}$ & O. ventosa & P. latifolius & $\begin{array}{l}\boldsymbol{P} \text { tricuspidatus } \\
\text { P. trifoliatus }\end{array}$ & $\begin{array}{l}\boldsymbol{R} . \\
\text { melanophloeos }\end{array}$ \\
\hline $\mathrm{N}$ & $188.2 \pm 29.11$ & $212.27 \pm 29.82$ & $169.47 \pm 15.06$ & $203.67 \pm 28.91$ & $163.8 \pm 26.33$ & $146 \pm 25.64$ & $125.87 \pm 23.87$ & $122.33 \pm 19.46$ \\
\hline S & $66.73 \pm 7.68$ & $79.27 \pm 8.92$ & $64.53 \pm 4.26$ & $69.13 \pm 7.67$ & $56.93 \pm 4.75$ & $58.67 \pm 6.92$ & $48.8 \pm 5.09$ & $55.2 \pm 7.24$ \\
\hline $\begin{array}{l}\text { Herbivore } \\
\text { N }\end{array}$ & $46.53 \pm 8.45$ & $53.07 \pm 10.59$ & $52.93 \pm 7.15$ & $55.93 \pm 12.15$ & $58.47 \pm 13.67$ & $35.27 \pm 7.22$ & $35.87 \pm 10.45$ & $31.13 \pm 5.19$ \\
\hline Herbivore S & $13.2 \pm 1.52$ & $14.73 \pm 2.05$ & $13.87 \pm 1.21$ & $13.33 \pm 1.6$ & $13.73 \pm 1.36$ & $12.47 \pm 1.59$ & $10.67 \pm 1.11$ & $11.53 \pm 1.25$ \\
\hline Predator N & $68.8 \pm 13.76$ & $84.4 \pm 12.22$ & $56.53 \pm 6.2$ & $78.79 \pm 13.829$ & $65 \pm 8.14$ & $54 \pm 10.44$ & $43.67 \pm 8.43$ & $52 \pm 11.40$ \\
\hline Predator S & $30.53 \pm 4.31$ & $39.4 \pm 5.08$ & $30 \pm 2.84$ & $35.2 \pm 4.62$ & $31.3 \pm 2.82$ & $27.27 \pm 4.01$ & $21.13 \pm 2.99$ & $29.87 \pm 4.68$ \\
\hline $\begin{array}{l}\text { Detritivore } \\
\text { N }\end{array}$ & $44.07 \pm 7.43$ & $42.4 \pm 6.55$ & $39.2 \pm 5.26$ & $40.27 \pm 6.04$ & $41.27 \pm 5.21$ & $27.2 \pm 3.38$ & $21.93 \pm 3.64$ & $34.73 \pm 5.38$ \\
\hline $\begin{array}{l}\text { Detriti- } \\
\text { vore S }\end{array}$ & $12.8 \pm 1.29$ & $14.67 \pm 1.49$ & $13.07 \pm 0.84$ & $12.67 \pm 1.33$ & $12.47 \pm 1.11$ & $11.53 \pm 1.25$ & $7.93 \pm 0.97$ & $12.27 \pm 1.46$ \\
\hline Tourist N & $12.27 \pm 3.77$ & $11.73 \pm 2.16$ & $6.47 \pm 2.07$ & $5.27 \pm 0.9$ & $10.13 \pm 3.31$ & $5.67 \pm 0.98$ & $16.8 \pm 6.26$ & $7.53 \pm 1.42$ \\
\hline Tourist S & $5.2 \pm 0.9$ & $6.53 \pm 1.05$ & $3.6 \pm 0.71$ & $3.73 \pm 0.51$ & $5.07 \pm 1.09$ & $3 \pm 0.38$ & $5.53 \pm 0.97$ & $4 \pm 0.67$ \\
\hline Ant N & $8.73 \pm 2.41$ & $10.53 \pm 3.29$ & $6.87 \pm 1.63$ & $16.13 \pm 5.13$ & $7.87 \pm 4.33$ & $15.73 \pm 6.31$ & $4.53 \pm 1$ & $8.13 \pm 4.89$ \\
\hline Ant S & $2.47 \pm 0.36$ & $1.53 \pm 0.24$ & $2.07 \pm 0.33$ & $2.73 \pm 0.44$ & $1.93 \pm 0.36$ & $2.73 \pm 0.57$ & $1.67 \pm 0.33$ & $1.47 \pm 0.34$ \\
\hline
\end{tabular}

Table 2. Summary statistics of abundance and species density (mean \pm s.e.m.) sampled per individual tree from each of the respective tree species $(n=15)$ for the respective canopy arthropod guilds. $N=$ Number of specimens (abundance); $\mathrm{S}=$ Species density.

detritivores and tourists (Supplementary Figs. S12-S13 online). Species density of all guilds negatively correlated with plot canopy cover, except for ants, which were not affected by any of the variables here. Species density of predators positively correlated with focal tree cover, host same-species cover and an increase in tree species per plot, with overall patterns seemingly driven by predator responses (Table 3). 


\begin{tabular}{|c|c|c|c|c|c|c|c|c|c|}
\hline \multirow[b]{2}{*}{ Guild } & \multirow[b]{2}{*}{ Variable } & \multicolumn{4}{|c|}{ Abundance } & \multicolumn{4}{|c|}{ Species density } \\
\hline & & df & Chi-square & $\operatorname{Pr}(>$ Chisq $)$ & Sig & df & Chi-square & $\operatorname{Pr}(>$ Chisq $)$ & Sig \\
\hline \multirow{5}{*}{ Overall } & Focal tree species & 7 & 14.41 & 0.04 & * & 7 & 157.61 & $<0.001$ & $* * *$ \\
\hline & Focal tree cover & 1 & 1.31 & 0.25 & ns & 1 & 20.72 & $<0.001$ & $* * *$ \\
\hline & Host same-species cover & 1 & 0.50 & 0.48 & ns & 1 & 11.23 & $<0.001$ & $* * *$ \\
\hline & Plot richness & 1 & 1.09 & 0.30 & ns & 1 & 10.12 & $<0.01$ & $* *$ \\
\hline & Plot cover & 1 & $(-) 11.96$ & $<0.001$ & $* * *$ & 1 & $(-) 99.45$ & $<0.001$ & $* * *$ \\
\hline \multirow{5}{*}{ Herbivore } & Focal tree species & 7 & 14.59 & 0.04 & * & 7 & 21.37 & $<0.01$ & $* *$ \\
\hline & Focal tree cover & 1 & 0.32 & 0.57 & ns & 1 & 2.00 & 0.157 & ns \\
\hline & Host same-species cover & 1 & 2.22 & 0.14 & ns & 1 & 3.28 & 0.07 & ns \\
\hline & Plot richness & 1 & 0.26 & 0.61 & $\mathrm{~ns}$ & 1 & 0.16 & 0.69 & ns \\
\hline & Plot cover & 1 & $(-) 10.69$ & 0.001 & $* *$ & 1 & $(-) 28.24$ & $<0.001$ & $* * *$ \\
\hline \multirow{5}{*}{ Predator } & Focal tree species & 7 & 13.65 & 0.06 & ns & 7 & 118.2 & $<0.001$ & $* * *$ \\
\hline & Focal tree cover & 1 & 1.3 & 0.25 & ns & 1 & 15.6 & $<0.001$ & $* * *$ \\
\hline & Host same-species cover & 1 & 0.01 & 0.93 & ns & 1 & 4.19 & $<0.05$ & * \\
\hline & Plot richness & 1 & 0.5 & 0.48 & ns & 1 & 13.53 & $<0.001$ & $* * *$ \\
\hline & Plot cover & 1 & $(-) 6.53$ & 0.01 & * & 1 & $(-) 51.5$ & $<0.001$ & $* * *$ \\
\hline \multirow{5}{*}{ Detritivore } & Focal tree species & 7 & 24.82 & $<0.001$ & $* * *$ & 7 & 38.01 & $<0.001$ & $* * *$ \\
\hline & Focal tree cover & 1 & 3.11 & 0.08 & ns & 1 & 2.65 & 0.01 & ns \\
\hline & Host same-species cover & 1 & $(-) 0.65$ & 0.42 & ns & 1 & 0.64 & 0.43 & ns \\
\hline & Plot richness & 1 & 1.01 & 0.32 & ns & 1 & $(-) 0.17$ & 0.68 & ns \\
\hline & Plot cover & 1 & $(-) 6.62$ & 0.01 & * & 1 & $(-) 9.3$ & $<0.01$ & $* *$ \\
\hline \multirow{5}{*}{ Tourists } & Focal tree species & 7 & 19.55 & $<0.01$ & ** & 7 & 36.18 & $<0.001$ & $* * *$ \\
\hline & Focal tree cover & 1 & 0.06 & 0.82 & ns & 1 & 0.32 & 0.57 & ns \\
\hline & Host same-species cover & 1 & 0.45 & 0.50 & ns & 1 & 1.29 & 0.25 & ns \\
\hline & Plot richness & 1 & $(-) 0.04$ & 0.85 & ns & 1 & 1.43 & 0.23 & ns \\
\hline & Plot cover & 1 & $(-) 7.97$ & $<0.01$ & $* *$ & 1 & $(-) 9.57$ & $<0.01$ & $* *$ \\
\hline \multirow{5}{*}{ Ants } & Focal tree species & 7 & 13.34 & 0.06 & ns & 7 & 12.83 & 0.08 & ns \\
\hline & Focal tree cover & 1 & 0.05 & 0.82 & ns & 1 & 3.82 & 0.05 & ns \\
\hline & Host same-species cover & 1 & 1.33 & 0.25 & ns & 1 & 2.29 & 0.13 & ns \\
\hline & Plot richness & 1 & 7.29 & $<0.01$ & $* *$ & 1 & 1.36 & 0.24 & ns \\
\hline & Plot cover & 1 & $(-) 0.90$ & 0.32 & ns & 1 & $(-) 2.01$ & 0.16 & ns \\
\hline
\end{tabular}

Table 3. Results of the Generalized linear mixed modelling indicating chi-square values of each of the model variables for the respective arthropod guilds for abundance and species density data, including significance for each model variable. '. $P<0.01$, '*' $P<0.05$, “**' $P<0.01$, '***' $P<0.001$. (-) represents a negative correlation.

Similar to the other arthropod diversity measures, assemblage composition differed significantly for focal tree species identity, with all guilds, except the ants, revealing differences (Supplementary table S2 online). Tree species with the most dissimilar overall assemblage composition was $C$. dentata. Herbivores from C. capensis were most divergent in terms of their assemblage composition from those collected from other host species, with herbivore assemblages from R. melanophloeos overlapping considerably with those from other hosts (Fig. 1). Predator assemblage composition in canopies of $C$. dentata and $O$. ventosa differed substantially from those in canopies of other host tree species, and detritivore assemblages in canopies of $P$. trifoliatus was significantly different than those in the canopies of most other tree species (Fig. 1). Tourist assemblage composition showed the smallest response to different host tree species (Supplementary table S2 online; Fig. 1). Focal tree canopy cover affected only ant assemblage composition. Host same-species cover within a plot significantly explained overall, herbivore, predator and ant assemblage composition on focal trees (Table 4). Plot tree species richness explained variation only for herbivore assemblage composition. Assemblage composition of all arthropod guilds was significantly explained by total plot canopy cover.

Effect of intraspecific physiological variation on arthropod diversity. Overall arthropod abundance was significantly positively correlated with foliar $\mathrm{N}$, but negatively correlated with foliar $\mathrm{C}$ for $\mathrm{C}$. capensis and O. ventosa (Table 5). The converse was the case for association between overall arthropods collected from P. tricuspidatus canopies, in which overall arthropod abundances negatively correlated with foliar $\mathrm{N}$, and positively to foliar C. Overall arthropod abundance significantly correlated with foliar $\delta 13 \mathrm{C} / 12 \mathrm{C}$ in all tree canopies. However, in certain host species these correlations were positive, while in others negative. Among herbivores, abundance positively correlated with foliar $\mathrm{N}$ but negatively with foliar $\mathrm{C}$ in some host species (C. capensis, O. c macrocarpa and O. ventosa), and a converse pattern in others (P. tricuspidatus and P. trifoliatus) (Table 5). Herbivore abundances significantly correlated with foliar total $\mathrm{C}$ in all tree canopies, except $C$. dentata. These 

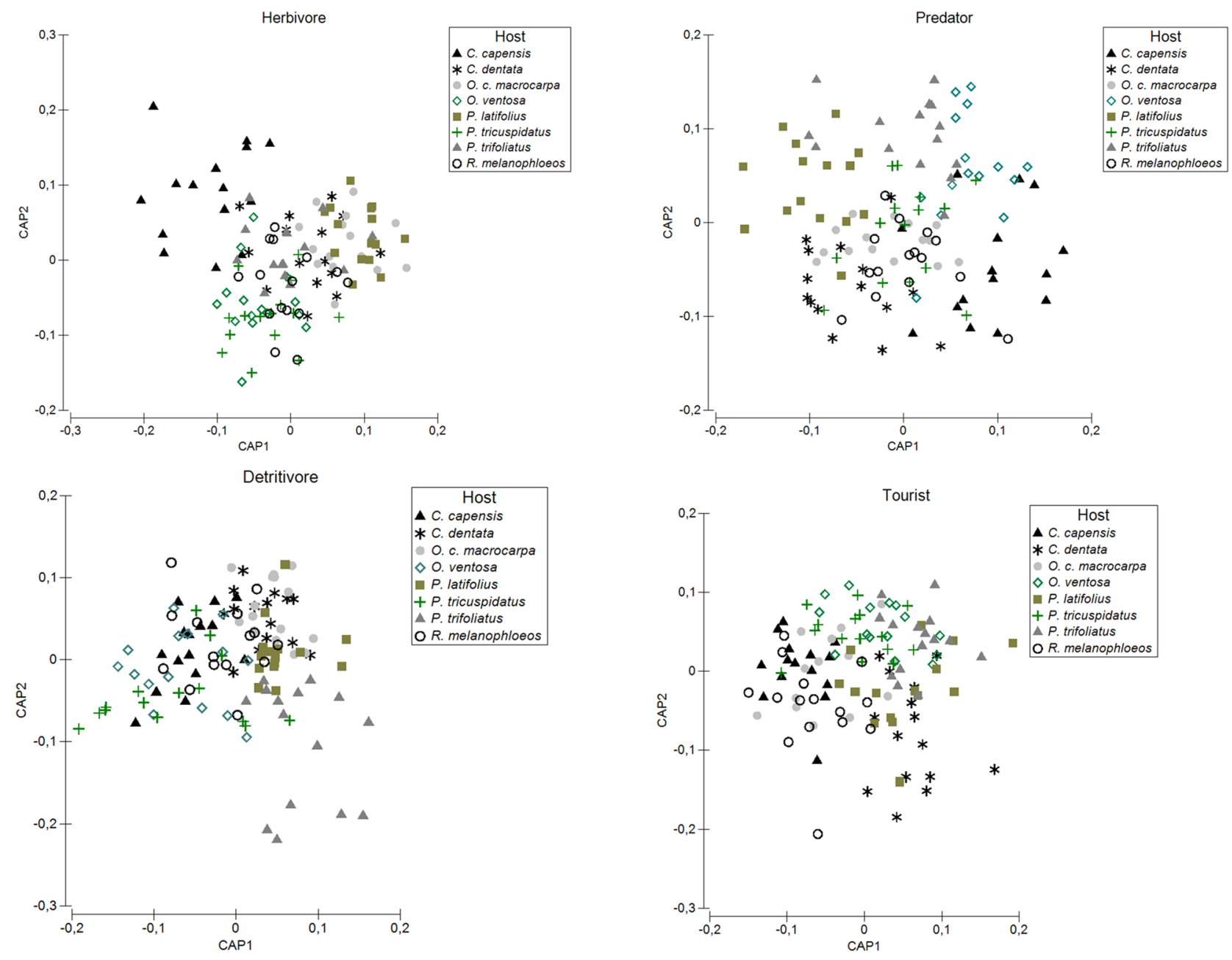

Figure 1. Visualization of assemblage composition results for the herbivore, predator, detritivore and tourist guilds using Canonical Analysis of Principal coordinates (CAP) between the eight tree species based on BrayCurtis dissimilarities.

responses ranged from being either positive or negative, depending on identity of host species. Herbivore abundance correlated positively (C. capensis, O. c. macrocarpa and O. ventosa), negatively (P. tricuspidatus, P. trifoliatus and $R$. melanophloeos) or neutral (C. dentata and P. latifolius) towards changes in $\mathrm{C} / \mathrm{N}$ ratio. Ants were the guild most responsive to foliar $\delta 15 \mathrm{~N} / 14 \mathrm{~N}$, with five tree species showing significant correlations. However, these correlations were either positive or negative, again depending on host tree species (Table 5).

Overall species density both positively and negatively correlated with foliar $\mathrm{N}$, depending on host tree species (Table 6). Herbivore species density positively correlated with foliar $\mathrm{N}$ in only one host species, P. latifolius, and was negatively correlated to foliar C, but in C. capensis canopies only. Predators showed mixed patterns in response to variation in foliar $\mathrm{N}, \delta 15 \mathrm{~N} / 14 \mathrm{~N}, \delta 13 \mathrm{C} / 12 \mathrm{C}$ and $\mathrm{C} / \mathrm{N}$. For example, predator species density was positively correlated with $\delta 13 \mathrm{C} / 12 \mathrm{C}$ in canopies of $O$. ventosa, $P$. trifoliatus and $P$. latifolius, whereas a negative correlation in canopies of O. c. marcocarpa was found (Table 6).

Intraspecific responses revealed the most important physiological variable explaining variation in arthropod assemblage composition was $\delta 15 \mathrm{~N} / 14 \mathrm{~N}$, with all eight species showing significance for at least one guild (Table 7). For four tree species, ant assemblage composition was best explained by the variable $\delta 15 \mathrm{~N} / 14 \mathrm{~N}$. In $C$. dentata, $P$. latifolius, . tricuspidatus and $R$. melanophloeos canopies, herbivore assemblage composition was best explained by $\delta 15 \mathrm{~N} / 14 \mathrm{~N}$. Changes in $\delta 13 \mathrm{C} / 12 \mathrm{C}$ was associated with changes in assemblage composition of overall arthropod, herbivore, detritivore and predator guilds, although on only one host, P. tricuspidatus (Table 7).

\section{Discussion}

Diversity and distribution of canopy arthropods in an African warm temperate forest are remarkably intricate, with each tree species playing a central role in determining their diversity (density, abundance) and assemblage composition. Moreover, our results indicate that, underlying the role of different tree species in dictating patterns in diverse, higher trophic levels, are the physiology of a tree individual, its immediate surrounds within diverse forests, and the interactions between tree physiology and immediate surrounds. Based on this, predictions regarding canopy arthropod responses to future change appears difficult to confidently make. 


\begin{tabular}{|c|c|c|c|c|c|c|c|}
\hline Variable & Statistic & Overall & Herbivores & Predators & Detritivores & Tourists & Ants \\
\hline \multirow{5}{*}{ Focal tree cover } & AICc & 972.23 & 959.06 & 974.1 & 945.89 & 956.19 & 931.17 \\
\hline & SS & 4136.5 & 4293.3 & 3202.7 & 3636.9 & 2918.3 & 6094.9 \\
\hline & Pseudo-F & 1.28 & 1.48 & 0.97 & 1.40 & 1.03 & $2.65^{* *}$ \\
\hline & Prop. Variance & 0.01 & 0.01 & 0.01 & 0.01 & 0.01 & 0.02 \\
\hline & Cum. Variance & 0.01 & 0.01 & 0.01 & 0.01 & 0.01 & 0.02 \\
\hline \multirow{5}{*}{ Host same-species cover } & AICc & 972.62 & 959.09 & 975.25 & 946.77 & 956.95 & 931.29 \\
\hline & SS & 5411.9 & 5881.5 & 5045.3 & 3125.9 & 3743.4 & 4456.7 \\
\hline & Pseudo-F & $1.68^{* *}$ & $2.04^{* \star}$ & $1.53^{* *}$ & 1.2 & 1.32 & $1.95^{*}$ \\
\hline & Prop. Variance & 0.01 & 0.02 & 0.01 & 0.01 & 0.01 & 0.02 \\
\hline & Cum. Variance & 0.02 & 0.03 & 0.02 & 0.02 & 0.02 & 0.04 \\
\hline \multirow{5}{*}{ Plot richness } & AICc & 973.58 & 959.4 & 976.4 & 947.69 & 958.51 & 932.44 \\
\hline & SS & 3684.1 & 5110.3 & 3200.5 & 3075.7 & 1600.9 & 2203.3 \\
\hline & Pseudo-F & 1.14 & $1.79^{*}$ & 0.97 & 1.18 & 0.56 & 0.96 \\
\hline & Prop. Variance & 0.01 & 0.01 & 0.01 & 0.01 & 0.00 & 0.01 \\
\hline & Cum. Variance & 0.03 & 0.04 & 0.03 & 0.03 & 0.02 & 0.05 \\
\hline \multirow{5}{*}{ Plot cover } & AICc & \begin{tabular}{|l|}
973.87 \\
\end{tabular} & 959.51 & 977.1 & 947.96 & 958.39 & 932.6 \\
\hline & SS & 5843 & 5656.7 & 4685.2 & 4739.4 & 6246.6 & 4407.7 \\
\hline & Pseudo-F & $1.83^{* * *}$ & $1.99^{* *}$ & $1.43^{*}$ & $1.84^{*}$ & $2.22^{* *}$ & $1.94^{*}$ \\
\hline & Prop. Variance & 0.02 & 0.02 & 0.01 & 0.02 & 0.02 & 0.01 \\
\hline & Cum. Variance & 0.05 & 0.06 & 0.04 & 0.05 & 0.04 & 0.06 \\
\hline
\end{tabular}

Table 4. Results of the distance-based linear modelling sequential tests indicating the significance of the selected variables on assemblage composition of different arthropod guilds from the canopies, regardless of species. '*' $P<0.05$, '**' $P<0.01$, '***' $P<0.001$.

Here, most tree species hosted unique arthropod assemblages, with the herbivores and the predators showing the most dissimilarity between tree species. In agreement with most global literature, in which herbivorous arthropods are understood to be at least as specialized as pollinators ${ }^{9}$, these dissimilarities could be driven by host specificity. Host specificity among herbivores arises from interspecific differences in tree morphology, physiology, and phenology, with adaptations to these becoming increasingly host species-specific over time ${ }^{10,26}$. From the assemblage composition analyses, and similar to previous work ${ }^{27}$, we suggest that arthropod specialization towards different tree species does not seem to be restricted only to folivores, but might also shift beyond lower trophic levels to include predatory arthropods ${ }^{28}$. Also, the assemblages of herbivores and predators, along with the ants, but not detritivores or tourists, were strongly explained by host same-species cover (the canopy cover of tree species similar to focal tree species within a plot). This might further indicate host specificity, relating to the resource concentration hypothesis: that the distribution of species will reflect the density of its preferred resources, such as herbivores on host trees ${ }^{29}$. Subsequently, many arthropod guilds can be considered host specific, albeit secondarily, highlighting the importance of retaining different tree species in the conservation of higher trophic levels. Losing a single tree species from these scattered forest patches could cause the local extirpation of unique assemblages, which will include numerous cryptic and undescribed species.

Contrary to resource concentration hypotheses, and increases in microhabitats with denser foliage ${ }^{25}$, we found a strong negative correlation between plot cover and arthropod diversity on host trees. This is similar to Finnish forests, where gall abundance on spruce trees decreased with increased cover ${ }^{30}$. Decreased arthropod diversity associated with increased canopy cover is often related to decreases in light exposure ${ }^{21}$. We show that foliar $\mathrm{C}$ concentration in leaves was lowest where light exposure was least (re: high plot cover), a finding supported elsewhere, with reductions in carbon-based phenol concentrations in less light-exposed leaves ${ }^{31,32}$. Interestingly, foliar $\mathrm{C}$, as well as arthropod diversity, increased on focal trees with less surrounding canopy cover. In line with these findings, increased carbon-based defences and greater herbivore damage occurred among tree seedlings in tree-fall gaps compared to forest interiors in a temperate Chilean rainforest ${ }^{20}$. Therefore, despite increases in carbon-based defences in more light exposed plants, herbivore diversity does not necessarily respond negatively. This suggests that arthropod diversity is strongly driven by canopy structural heterogeneity, creating numerous microhabitats, ranging from highly exposed to light to completely shaded ${ }^{33}$. Our results concur with this, and show all arthropod guilds' assemblage compositions were significantly explained by variations in plot cover. More directly, light exposure leads to increased temperatures that have positive effects on development of numerous arthropod tax $\mathrm{a}^{34}$, while homogenization of forests, through decreases in both structural diversity and tree richness, can reduce arthropod diversity ${ }^{35}$. This is concerning, with losses of the natural heterogeneity of unmanaged, old-growth forests predictably negatively impacting optimal ecosystem-level conservation, while plantation forests and large-scale homogenization are increasing worldwide ${ }^{36}$.

With the exception of total plot canopy cover, few other plot-scale characteristics influenced arthropod abundance and density of focal trees. However, it is interesting that predator species density was most affected by plot-scale characteristics, with density increasing with increased tree species richness around the focal tree. 


\begin{tabular}{|c|c|c|c|c|c|c|c|c|c|}
\hline Guild & Variable & C. capensis & C. dentata & $\begin{array}{l}\text { O. c. } \\
\text { macrocarpa }\end{array}$ & O. ventosa & P. latifolius & \begin{tabular}{|l|} 
P. \\
tricuspidatus
\end{tabular} & \begin{tabular}{|l|} 
trifoliatus \\
\end{tabular} & $\begin{array}{l}R . \\
\text { melanophloeos }\end{array}$ \\
\hline \multirow{5}{*}{ Overall } & $\mathrm{N}$ & $5.58^{* * *}$ & & $-2.95^{\star *}$ & $2.95^{* *}$ & & $-6.59^{* * *}$ & $-5.07^{\star * *}$ & \\
\hline & $\delta 15 \mathrm{~N} / 14 \mathrm{~N}$ & $3.04^{* *}$ & $-3.63^{* * *}$ & $-2.84^{\star \star}$ & & & $5.76^{* * *}$ & & $-16.54^{* * *}$ \\
\hline & C & $-8.10^{* * *}$ & $-4.67^{* * *}$ & & $-6.64^{* * *}$ & $4.08^{* * *}$ & $4.96^{* * *}$ & & \\
\hline & $\delta 13 \mathrm{C} / 12 \mathrm{C}$ & $-5.47^{* * *}$ & $2.59^{* *}$ & $-4.49^{* * *}$ & $5.21^{\star * \star}$ & $10.95^{* * *}$ & $-5.54^{* * \star}$ & $14.00^{* * *}$ & $3.60^{* * *}$ \\
\hline & $\mathrm{C} / \mathrm{N}$ & $5.27^{* * *}$ & & $-6.36^{* * *}$ & $3.52^{\star * *}$ & $-9.64^{* * *}$ & $-9.12^{* * *}$ & $-4.51^{\star \star \star}$ & \\
\hline \multirow{5}{*}{ Herbivores } & $\mathrm{N}$ & $5.17^{* * *}$ & $-6.47^{* * *}$ & $5.57^{* * *}$ & $2.76^{* *}$ & & $-3.76^{* * *}$ & $-3.44^{* * *}$ & \\
\hline & $\delta 15 \mathrm{~N} / 14 \mathrm{~N}$ & & $-3.26^{* *}$ & $-3.29^{* * *}$ & & $3.44^{* * *}$ & & & \\
\hline & C & $-6.93^{* * *}$ & & $-6.50^{* * *}$ & $-5.01^{* * *}$ & $7.50^{* * *}$ & $8.70^{* * *}$ & $4.21^{* * *}$ & $-2.60^{\star *}$ \\
\hline & $813 \mathrm{C} / 12 \mathrm{C}$ & $-5.77^{* * *}$ & $8.97^{* * *}$ & & $-6.02^{\star * *}$ & $4.19^{* * *}$ & $-7.75^{* * *}$ & $8.36^{* * *}$ & \\
\hline & $\mathrm{C} / \mathrm{N}$ & $4.79^{* * *}$ & & $5.48^{* * *}$ & $4.00^{* * *}$ & & $-5.19^{* * *}$ & $-3.39^{* * *}$ & $-5.33^{* * *}$ \\
\hline \multirow{5}{*}{ Predators } & $\mathrm{N}$ & & $3.97^{* * *}$ & $2.72^{\star \star}$ & & & $-7.71^{* * *}$ & & \\
\hline & $\delta 15 \mathrm{~N} / 14 \mathrm{~N}$ & & & & & & $10.43^{* * *}$ & $-4.56^{* * *}$ & $-10.55^{* * *}$ \\
\hline & C & $-5.27^{* * *}$ & $-5.12^{* * *}$ & & $-4.41^{* * *}$ & & & $-4.84^{* * *}$ & \\
\hline & $\delta 13 \mathrm{C} / 12 \mathrm{C}$ & $-6.57^{* * *}$ & & $-4.66^{* * *}$ & $6.92^{* * *}$ & $5.91^{* * *}$ & & $6.83^{* * *}$ & \\
\hline & $\mathrm{C} / \mathrm{N}$ & $-4.50^{* * *}$ & $3.74^{\star * \star}$ & & & $-7.87^{\star * *}$ & $-8.60^{* * *}$ & & \\
\hline \multirow{5}{*}{$\begin{array}{l}\text { Detriti- } \\
\text { vores }\end{array}$} & $\mathrm{N}$ & & & $-5.28^{* * *}$ & $3.75^{* * *}$ & $3.56^{* * *}$ & & & \\
\hline & $\delta 15 \mathrm{~N} / 14 \mathrm{~N}$ & & $-3.02^{\star *}$ & & & & & & $-6.50^{\star * *}$ \\
\hline & C & $-4.65^{\star * *}$ & & $4.88^{* * *}$ & $-3.41^{* * *}$ & $-4.41^{* * *}$ & & $-2.21^{*}$ & \\
\hline & $\delta 13 \mathrm{C} / 12 \mathrm{C}$ & $4.07^{* * *}$ & $-2.85^{* *}$ & $-2.50^{*}$ & $3.66^{* * *}$ & $4.01^{\star \star *}$ & & $4.41^{\star * *}$ & \\
\hline & $\mathrm{C} / \mathrm{N}$ & & & $-5.58^{* * *}$ & $3.76^{* * *}$ & & $-2.88^{* * *}$ & & \\
\hline \multirow{5}{*}{ Tourists } & $\mathrm{N}$ & & $3.56^{* * *}$ & & & $3.29^{* *}$ & & & \\
\hline & $\delta 15 \mathrm{~N} / 14 \mathrm{~N}$ & $3.69^{* * *}$ & & & & & & & $-4.11^{* * *}$ \\
\hline & C & & $-4.15^{* * *}$ & $-3.44^{* * *}$ & & $2.59^{* *}$ & & $-2.72^{* *}$ & \\
\hline & $\delta 13 \mathrm{C} / 12 \mathrm{C}$ & $-5.73^{* * *}$ & $2.75^{* *}$ & & & $5.30^{* * *}$ & & $7.50^{* \star \star}$ & \\
\hline & $\mathrm{C} / \mathrm{N}$ & & $3.72^{* * *}$ & $-5.07^{* * *}$ & & $2.98^{* *}$ & & $5.06^{* * *}$ & \\
\hline \multirow{5}{*}{ Ants } & $\mathrm{N}$ & $-5.00^{* * *}$ & $2.01^{*}$ & & & $-6.07^{* * *}$ & & & \\
\hline & $\delta 15 \mathrm{~N} / 14 \mathrm{~N}$ & $2.45^{*}$ & & $-3.43^{* * *}$ & $3.97^{* * *}$ & $-3.41^{* * *}$ & & & $-2.71^{\star *}$ \\
\hline & C & & & $-3.19^{* *}$ & $-5.23^{* * *}$ & & $7.83^{* * *}$ & & $-1.97^{\star}$ \\
\hline & $813 \mathrm{C} / 12 \mathrm{C}$ & $-2.88^{* *}$ & $-4.79^{* * *}$ & & $7.84^{* \star *}$ & $3.00^{* *}$ & $-7.99^{* * *}$ & & $3.69^{* * *}$ \\
\hline & $\mathrm{C} / \mathrm{N}$ & & & & & $-6.15^{* * *}$ & $-5.01^{\star * *}$ & & \\
\hline
\end{tabular}

Table 5. Results of the model selection procedure (based on second order Akaike Information Criterion) indicating correlations of measured plant characteristics on canopy arthropod abundances for each of the respective arthropod guilds among eight tree species. Reported $z$-values. '*' $P<0.05$, '**' $P<0.01$, '***' $P<0.001$.

This supports the enemies hypothesis, which predicts increases in predator diversity in more diverse plant communities $^{37}$. For example, an increase in localized tree richness will have a direct effect on the number of micro-habitats, and provide more variation in prey base and temporal stability in prey availability ${ }^{37}$. Interestingly, plot tree richness explained variation in the assemblages of only one guild, the herbivores. The relationship between plant richness, herbivore assemblages and predator diversity was not specifically tested here, and future work could shed light on these interesting patterns.

Whereas species density of especially the predators, and little else, seemed to be driven by plot-scale variables, ecophysiological variables strongly correlated with the abundances more than with densities of various guilds. Here, we show correlations between intraspecific variability of leaf physiological traits and abundances of all arthropod guilds. Foliar resource availability and its effect on higher trophic levels, although widely studied, is poorly understood. Differences in physiological traits can be due to host genetics ${ }^{38}$, but often also due to differences in nutrient or moisture availability ${ }^{22}$, expected to increase fluctuations beyond species' thresholds under global climate change ${ }^{39}$. Differences in $\mathrm{N}$ between trees, for example, could greatly affect eventual ecosystem processes, especially nutrient cycling, due to $\mathrm{N}$ investment in metabolic compounds ${ }^{40}$, with $\mathrm{N}$ concentration often but not exclusively an indication of leaf quality for insect herbivores ${ }^{19}$. Foliar $\mathrm{N}$ here had differential impacts on arthropods, exhibiting stronger correlations compared to relatively low or no impacts in other tree species. Essentially, not only a tree species' visibly unique traits (i.e. phenology, morphology), but also its physiological differences compared to other species, appear to drive especially arthropod abundances in higher trophic levels.

With $\delta 13 \mathrm{C} / 12 \mathrm{C}$ often used as a general proxy for moisture stress in plants ${ }^{23}$, our results indicate that arthropod diversity will likely respond differentially to future drought episodes depending on respective host tree species. For example, herbivore density and abundance increased with decreased $\delta 13 \mathrm{C} / 12 \mathrm{C}$ on one species, but on another species, there was a converse relationship. Under future scenarios of moisture stress, altering foliar $\delta 13 \mathrm{C} / 12 \mathrm{C}$ in any one direction might therefore not have predictable herbivore responses, i.e. that stressed trees are more susceptible to herbivore attack, or that stressed trees provide less nutritious leaves and dispel herbivores. Instead, we might expect to find a plethora of idiosyncratic responses to moisture stress, which includes tree 


\begin{tabular}{|c|c|c|c|c|c|c|c|c|c|}
\hline Guild & Variable & C. capensis & C. dentata & $\begin{array}{l}\text { O. c. } \\
\text { macrocarpa }\end{array}$ & O. ventosa & P. latifolius & \begin{tabular}{|l|} 
P. \\
tricuspidatus
\end{tabular} & \begin{tabular}{|l|} 
P. \\
trifoliatus \\
\end{tabular} & \begin{tabular}{|l|}
$R$. \\
melanophloeos \\
\end{tabular} \\
\hline \multirow{5}{*}{ Overall } & $\mathrm{N}$ & $3.57^{* * *}$ & $-2.52^{*}$ & & & $4.46^{* * *}$ & $-4.29^{* * *}$ & & \\
\hline & $\delta 15 \mathrm{~N} / 14 \mathrm{~N}$ & & $-4.26^{\star * \star}$ & & & & $5.64^{\star \star \star}$ & $-2.67^{* *}$ & $-3.69^{* * *}$ \\
\hline & C & $-5.85^{* * *}$ & & & & & & $-3.11^{\star *}$ & \\
\hline & $\delta 13 \mathrm{C} / 12 \mathrm{C}$ & $-2.50^{*}$ & & & $2.27^{*}$ & $4.89^{* * *}$ & & $5.39^{* * *}$ & \\
\hline & $\mathrm{C} / \mathrm{N}$ & & & $-2.63^{* *}$ & $3.89^{* * *}$ & & $-4.71^{* * *}$ & & $-1.97^{*}$ \\
\hline \multirow{4}{*}{ Herbivores } & $\mathrm{N}$ & & & & & $2.95^{* *}$ & & & \\
\hline & $\delta 15 \mathrm{~N} / 14 \mathrm{~N}$ & & & $-2.36^{\star}$ & & & & & \\
\hline & C & $-2.23^{*}$ & & & & & & & \\
\hline & $\mathrm{C} / \mathrm{N}$ & & & $-2.20^{*}$ & & & & & $-2.27^{*}$ \\
\hline \multirow{5}{*}{ Predators } & $\mathrm{N}$ & $2.41^{*}$ & & & & & $-3.27^{* *}$ & $-2.50^{*}$ & \\
\hline & $\delta 15 \mathrm{~N} / 14 \mathrm{~N}$ & & $-2.88^{* *}$ & & & & $4.20^{* \star *}$ & & $-6.19^{* * *}$ \\
\hline & C & $-5.63^{* * *}$ & & & & $2.32^{*}$ & & & \\
\hline & $\delta 13 \mathrm{C} / 12 \mathrm{C}$ & & & $-2.09^{*}$ & $2.35^{*}$ & $3.17^{* *}$ & & $3.53^{* * *}$ & \\
\hline & $\mathrm{C} / \mathrm{N}$ & & & $-2.30^{*}$ & $3.08^{* *}$ & $-2.71^{\star *}$ & $-3.68^{* * *}$ & & \\
\hline \multirow{3}{*}{$\begin{array}{l}\text { Detriti- } \\
\text { vores }\end{array}$} & $\delta 15 \mathrm{~N} / 14 \mathrm{~N}$ & & $-3.46^{\star * *}$ & & & & & & $-3.71^{* * *}$ \\
\hline & C & $-2.03^{*}$ & & & & & & & \\
\hline & $\mathrm{C} / \mathrm{N}$ & & $2.04^{*}$ & & $2.73^{*}$ & & & & \\
\hline \multirow{3}{*}{ Tourists } & $\delta 15 \mathrm{~N} / 14 \mathrm{~N}$ & & & $3.05^{* *}$ & & & & & \\
\hline & C & & & & & $2.13^{*}$ & & & \\
\hline & $\delta 13 \mathrm{C} / 12 \mathrm{C}$ & $-2.28^{*}$ & & & & $2.53^{*}$ & $2.28^{*}$ & & \\
\hline Ants & $\delta 15 \mathrm{~N} / 14 \mathrm{~N}$ & & & & & & & & $-2.55^{* *}$ \\
\hline
\end{tabular}

Table 6. Results of the model selection procedure (based on second order Akaike Information Criterion) indicating the effects of measured plant characteristics on canopy arthropod species density for each of respective arthropod guilds among eight tree species. Reported $z$-values. '*' $P<0.05$, '**' $P<0.01$, '***' $P<0.001$.

\begin{tabular}{|c|c|c|c|c|}
\hline Tree species & Guild & Variable & Pseudo-F & Variation explained (\%) \\
\hline \multirow{3}{*}{ C. capensis } & Predators & $\mathrm{C}$ & $1.62^{*}$ & 10.45 \\
\hline & Detritivores & $\delta 15 \mathrm{~N} / 14 \mathrm{~N}$ & $1.73^{\star}$ & 12.01 \\
\hline & Ants & $\delta 15 \mathrm{~N} / 14 \mathrm{~N}$ & $2.32^{\star}$ & 14.97 \\
\hline C. dentata & Herbivores & $\delta 15 \mathrm{~N} / 14 \mathrm{~N}$ & $1.86^{*}$ & 12.86 \\
\hline \multirow{2}{*}{ O.c. macrocarpa } & Predators & $\mathrm{C}$ & $1.64^{*}$ & 10.82 \\
\hline & Ants & $\delta 15 \mathrm{~N} / 14 \mathrm{~N}$ & $2.28^{\star}$ & 15.30 \\
\hline \multirow{3}{*}{ O. ventosa } & Overall & $\delta 15 \mathrm{~N} / 14 \mathrm{~N}$ & $1.55^{\star}$ & 10.55 \\
\hline & Predators & $\mathrm{N}$ & $1.42^{*}$ & 9.83 \\
\hline & Ants & $\delta 15 \mathrm{~N} / 14 \mathrm{~N}$ & $3.77^{\star *}$ & 22.24 \\
\hline P. latifolius & Herbivores & $\delta 15 \mathrm{~N} / 14 \mathrm{~N}$ & $1.77^{\star}$ & 11.85 \\
\hline \multirow{8}{*}{ P. tricuspidatus } & Overall & $\delta 15 \mathrm{~N} / 14 \mathrm{~N}$ & $1.56^{*}$ & 10.73 \\
\hline & & $813 \mathrm{C} / 12 \mathrm{C}$ & $2.10^{\star *}$ & 13.22 \\
\hline & Herbivores & $\delta 15 \mathrm{~N} / 14 \mathrm{~N}$ & $1.73^{\star}$ & 11.86 \\
\hline & & $\delta 13 \mathrm{C} / 12 \mathrm{C}$ & $1.83^{*}$ & 11.72 \\
\hline & Predators & $\delta 13 \mathrm{C} / 12 \mathrm{C}$ & $1.88^{*}$ & 12.27 \\
\hline & Detritivores & $\delta 13 \mathrm{C} / 12 \mathrm{C}$ & $2.55^{\star *}$ & 15.90 \\
\hline & Tourists & $\mathrm{N}$ & $2.79^{* *}$ & 17.69 \\
\hline & Ants & $\delta 15 \mathrm{~N} / 14 \mathrm{~N}$ & $2.63^{*}$ & 16.78 \\
\hline P. trifoliatus & Tourists & $\delta 15 \mathrm{~N} / 14 \mathrm{~N}$ & $2.24^{\star}$ & 14.98 \\
\hline \multirow{4}{*}{ R. melanophloeos } & Overall & $\delta 15 \mathrm{~N} / 14 \mathrm{~N}$ & $1.65^{\star}$ & 11.36 \\
\hline & Herbivores & $\delta 15 \mathrm{~N} / 14 \mathrm{~N}$ & $1.87^{\star}$ & 12.66 \\
\hline & Detritivores & $\delta 15 \mathrm{~N} / 14 \mathrm{~N}$ & $1.88^{\star}$ & 12.74 \\
\hline & Tourists & $\delta 15 \mathrm{~N} / 14 \mathrm{~N}$ & $2.45^{\star \star}$ & 15.36 \\
\hline
\end{tabular}

Table 7. Results of distance-based linear modelling (DistLM) sequential tests, indicating most descriptive plant physiological variable/s for each selected canopy arthropod guild assemblage composition among selected tree species. '. $P<0.01$, '‘' $P<0.05$, '**' $P<0.01$, ‘***' $P<0.001$. 


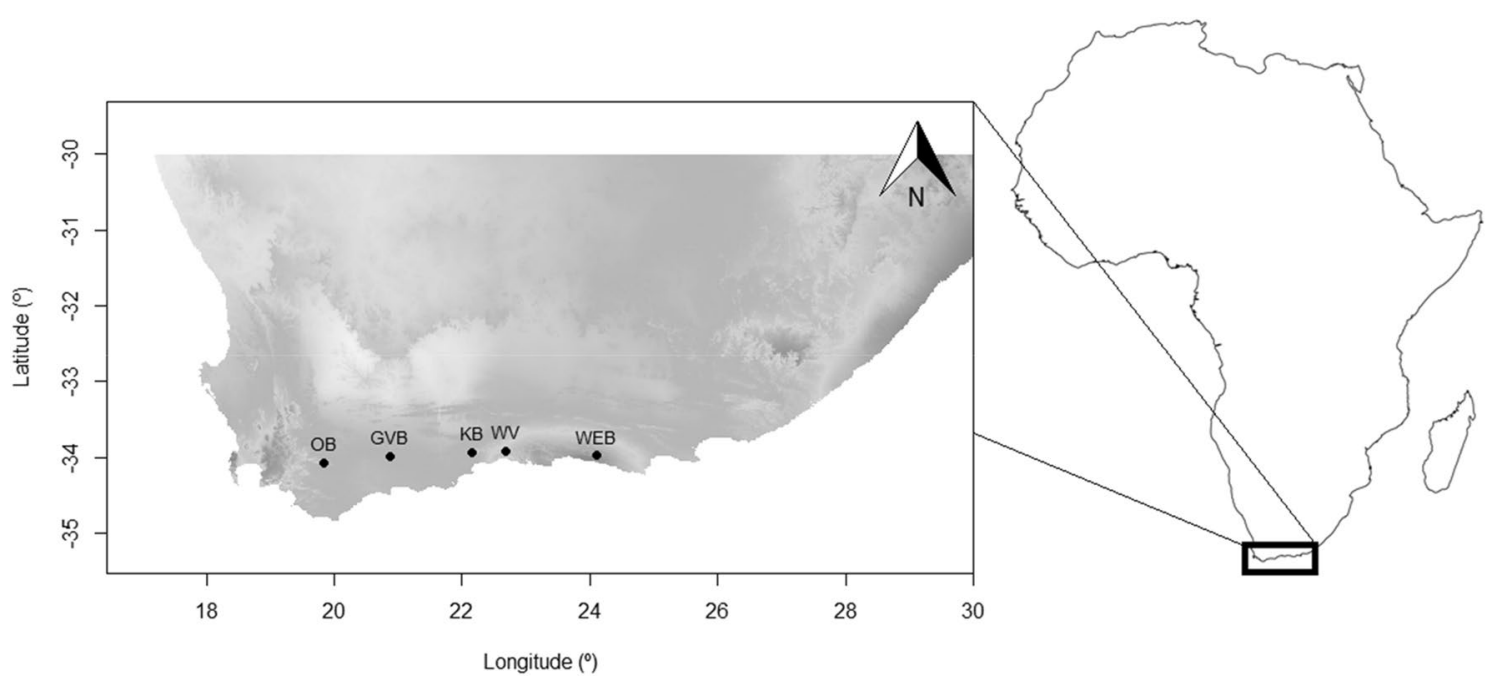

Figure 2. Study region in Africa, showing the five forests from which arthropods were sampled. $\mathrm{OB}=\mathrm{Oubos}$, $\mathrm{GVB}=$ Grootvadersbosch, $\mathrm{KB}=$ Kleinbos, $\mathrm{WV}=$ Woodville, $\mathrm{WEB}=$ Witelsbos. Mean annual temperature for southern Afro-temperate forests is $16.7^{\circ} \mathrm{C}$, characterized by cool winters $\left(8-20^{\circ} \mathrm{C}\right)$ and warm summer $(13-$ $25^{\circ} \mathrm{C}$ ) months. The three western study forests ranged in elevation between $370-410 \mathrm{~m}$ above sea level, and the two eastern forests, closer to the coast, are located ca. 250 m.a.s.l. Map generated using R statistical software (rstudio.com) version 3.6.2 through ggplot2, raster and rgdal packages with shape file imported from the GADM database (GADM.org).

intraspecific differences. Conditions in which trees are found may promote these differences, for example when grown closer to perennial streams, or forest edges. Trees in the current study were chosen based on a range of different local conditions (such as distance to streams, rockiness, slope), but these conditions were not considered here. It is well-known that certain tree species prefer wetter microsites within diverse forest communities, and during adverse dry spells, their overall fitness could be more, or less, resilient compared to trees growing in drier microsites. Other species, that grow in a range of microsites, from dry to wet, might reveal intraspecific responses to dry spells, from which differential arthropod responses toward individual trees can be expected. Thus, there will likely be no uniformity in response by canopy arthropod diversity towards increased environmental and climatic changes, as has been suggested for the interactions between herbivorous insects and trees globally ${ }^{15}$.

It is important to be clear on the interaction between carbon-based plant physiology and arthropod diversity in tree canopies, especially under predictions of elevated levels of CO2 globally ${ }^{41}$. Increases in CO2 in the atmosphere will promote plant productivity, likely without simultaneous increases in nutrient uptake ${ }^{42}$. In turn, this might increase the $\mathrm{C} / \mathrm{N}$ ratio in many plants, often an important indication of both food quality and plant defences $^{40}$. Exposing various Quercus-species to elevated levels of $\mathrm{CO} 2$ led not only to a rise in foliar $\mathrm{C} / \mathrm{N}$ ratios, but also to a decrease in associated insect herbivory ${ }^{43}$. Furthermore, insect herbivores will have reduced fitness under elevated $\mathrm{CO} 2$ levels, through reduced growth rates and longer development time, as well as reductions in food conversion efficiency ${ }^{44}$. However, increases in $\mathrm{C} / \mathrm{N}$ may trigger increased herbivore consumption rates, to compensate for diluted nitrogen concentrations in leaves ${ }^{45}$. More compensating strategies by insect herbivores, during increases in $\mathrm{C} / \mathrm{N}$, include increased nitrogen utilization efficiency ${ }^{46}$ and stimulation of enzymes detoxifying secondary metabolites in leaves ${ }^{47}$. This means that increased $\mathrm{C} / \mathrm{N}$ ratios would not necessarily guarantee decreased herbivore performance. Here, $\mathrm{C} / \mathrm{N}$ ratio correlations with arthropod diversity varied between positive, neutral, and negative, depending on the focal tree species, and showing great interspecific variability in foliar $\mathrm{C} / \mathrm{N}$. This suggests that tree species will respond differentially towards elevated CO2 levels, as they do to drought ${ }^{13}$, and lead to many stressors on existing plant-insect interactions.

In conclusion, under future change scenarios, multifaceted responses in canopy arthropod diversity, that are difficult to predict, can be expected. This is especially relevant in small, isolated forest patches, such as the Afro-temperate forests studied here, with limited opportunities for arthropod dispersal between forest patches. Moreover, for many arthropod species, being host-recurrent, shifting from one host species to another during stressful conditions will also not be possible ${ }^{48}$. Conversely, other, generalist arthropods might be able to move between host species, and become more numerous ${ }^{15}$. Ecological impacts of drought, or shifts in climatic regimes, could therefore cause arthropod populations to undergo great changes, threatening ecological integrity. However, host-specific responses of different arthropod guilds towards plant physiology make predictions on how future climates might be shaping canopy communities especially difficult. Our results indicate that these responses encompass factors associated with tree species, plot characteristics, and plant physiology, notwithstanding the direct impacts of environmental change on insect physiology and phenology.

\section{Methods}

Study area. This study was conducted in five southern Afro-temperate forests from Riviersonderend in the west (Lat -34.04; lon 19.83) to Witelsbos in the east (Lat -33.98; lon 24.11), in the southern Cape of South Africa (Fig. 2). Southern Afro-temperate forests grow on nutrient-poor soils and receive rain all year. Variations in 
nutrient availability for particular forest trees might arise from differences in leaf-litter nutrient release ${ }^{49}$, competition with other plants ${ }^{50}$, and/or moisture availability ${ }^{51}$, especially in nutrient-poor soils. Average annual rainfall at the five study sites for the five years leading up to sampling (2012-2016) was $1003.64 \mathrm{~mm} \pm 47.10$ (s.e.m.), with no significant differences between sites (Supplementary Fig. S14 online).

Tree selection and arthropod collection. Eight focal tree species were selected, including the three most dominant species in southern Afro-temperate forests (O. c. macrocarpa, R. melanophloeos and P. latifolius), and five species, of various levels of dominance and phylogenetic relatedness (Supplementary table S3 online), commonly encountered throughout the study region ${ }^{52}$. Three individuals of each species were selected per forest, considering general accessibility, tree size $(\mathrm{DBH}>50 \mathrm{~cm}$, height $>12 \mathrm{~m}<28 \mathrm{~m})$, understorey density $(<20 \%)$, and $>15 \mathrm{~m}$ apart. These trees also represent a range of different soil depths (according to rockiness of the terrain), distances from surface water (annual streams), and competition from other trees (canopy densities). Accordingly, 24 individual trees were selected per forest, with 15 individual trees per species across the five forests ( 120 tree individuals in total).

Trees were treated with insecticide fog early morning or late afternoon (05:00-07:00, or after 18:00), under windless conditions, to avoid fog scatter ${ }^{11}$. Trees were treated over two summer months, January and February 2017 , corresponding to peak activity for arthropods ${ }^{53}$. We used a Typhoon hand-held fogging machine $(45 \mathrm{~L} / \mathrm{hr}$ solution output) and a pyrethroid insecticide blend ( $1 \%$ deltamethrin, $0.6 \%$ permethrin, $6 \%$ piperonyl butoxide, $5 \%$ aromatic hydrocarbon solvent and $88 \%$ diesel), obtained from Dyna-Fog Africa. This machine provides a consistent, warm cloud of fog rising in cool ambient forest conditions. Fog was emitted at ground level for 2 min, to avoid lateral movement into neighbouring trees, while ensuring the entire tree was enveloped in the fog. Ground level fogging has limitations compared to rope-and-pulley systems ${ }^{54}$; fog may not reach all parts of the tree in similar densities. However, it enables quicker implementation and larger mobility of the handler to reach as many trees as possible during limited time of prevailing favourable conditions. Selected trees had no visible epiphytes, flowers, or fruit. Where understorey was present, vegetation was lodged away from the immediate fogging area, or physically removed. Two collecting sheets, each $320 \mathrm{~cm} \times 148 \mathrm{~cm}$ in size $\left(=9.47 \mathrm{~m}^{2}\right)$, were placed underneath the crown of each focal tree, while avoiding areas that had overlapping branches of other trees, and suspended ca. $1 \mathrm{~m}$ from the forest floor using steel stakes and rope to avoid litter fauna moving onto sheets. A waiting time of $50 \mathrm{~min}$ after insecticide application was given to ensure maximal collection time before larger arthropods started to recover. Arthropods on collecting sheets were transferred to collecting jars containing $70 \%$ ethanol.

Arthropods. Collected arthropods were sorted to morphospecies, and assigned to an arthropod order. Where possible, specimens were identified to family level, with spiders and ants identified to genus and/or species level. Additionally, all arthropods were grouped according to functional feeding guild using field guides ${ }^{55}$ and by examining their mouthparts ${ }^{56}$, specific to life stage. Nectarivores, frugivores, granivores, xylophages and phytophages, including combinations of these, were collectively classified under herbivores. All predators and parasitoids were classified under predators. Fungivores, scavengers, omnivores, scatophages and saprophages, including combinations of these, were classified as detritivores. Many fly species have unknown or no feeding strategies as adults. Therefore, considering the life stage collected, species that could not be confidently placed in the categories of herbivore, predator or detritivore, were placed in a separate category termed tourist, similar to previous canopy research ${ }^{57,58}$. All ants, having a wide range of diets and unique social structures, were treated as a separate group. Parasites and pollinators comprised relatively few individuals, and were excluded from guild analyses. However, they were included with all other guilds in the overall category. A reference collection of all morphospecies is in the Entomology Museum, Stellenbosch University, but spiders were deposited in the South African National Collection of Arachnida, Pretoria, and all hymenopterans, including the ants, at Iziko Museum, Cape Town.

Plant characteristics. We collected random, mature leaves from the lower branches of each individual focal tree using a pole pruner and a ladder. Leaves were air dried for 4 months in brown paper bags. Then, $0.02 \mathrm{~g}$ powdered dry leaf material was sent to the Stable Isotope Laboratory at the Department of Archaeology, University of Cape Town, South Africa to determine total nitrogen content $(\mathrm{N})$, total carbon content $(\mathrm{C})$, carbon: nitrogen ratio $(\mathrm{C} / \mathrm{N}), \delta 15 \mathrm{~N} / 14 \mathrm{~N}$ ratio $(\delta 15 \mathrm{~N} / 14 \mathrm{~N})$ and $\delta 13 \mathrm{C} / 12 \mathrm{C}$ ratio $(\delta 13 \mathrm{C} / 12 \mathrm{C})$ for each individual tree. Around each focal tree, a circular plot was established with a radius of $8 \mathrm{~m}$ (=plot size of ca. $200 \mathrm{~m}^{2}$ ). In each plot, the DBH of the focal tree was measured, its height estimated by a single observer using the mechanical method $^{59}$, and its percentage canopy cover estimated relative to the plot. Where the focal tree covered the whole plot, a cover rating of $100 \%$ was given, while a focal tree covering one quarter of the plot was given a cover rating of $25 \%$. For all other trees in the plot with a DBH larger than $15 \mathrm{~cm}$, we determined the species identity and percentage canopy cover. Thus, due to canopy overlap, the total cover per plot could be $>100 \%$.

Statistical analyses. Effect of tree identity and plot characteristics on tree physiological features. Data for $\mathrm{N}$ and $\mathrm{C}$ were subjected to Yeo-Johnson and inverse hyperbolic sine transformation respectively using the bestNormalize package in R version $3.5 .1^{60}$ to normalise distributions. Data for $\delta 15 \mathrm{~N} / 14 \mathrm{~N}, \mathrm{C} / \mathrm{N}$ and $\delta 13 \mathrm{C} / 12 \mathrm{C}$ had normal distributions, determined through Shapiro-Wilks W statistics, and not transformed. Linear mixed-effect modelling (LMMs) was used to evaluate the effect of various plot factors on these data, using the lme4 package in $\mathrm{R}^{61}$. Each model contained the variables host tree identity (species), host tree canopy cover, host same-species canopy cover in plot, total plot tree species richness, and plot canopy cover, with forest site (re: patch) included as random variable in the model ${ }^{62}$. Pairwise differences for the variables for which focal tree species had a significant influence were separated using a Tukey post-hoc test ${ }^{63}$. 
Effect of tree identity and plot characteristics on canopy arthropod diversity. Species estimates were performed in PRIMER 6, using the Chao 2 and Jacknife2 indices ${ }^{64}$. Both abundance and species density data for the respective guilds were tested for overdispersion in R. Overdispersed data were analysed using the negative binomial family, with equidispersed data analysed using the Poisson distribution family. Generalized linear mixed models were constructed for both abundance and species density using the package $\operatorname{lm} m T M B$ in $\mathrm{R}^{65}$. This was done for each of the respective guilds, with each model containing the variables host tree species, host tree canopy cover, host same-species cover in plot, plot tree species richness, and plot canopy cover, with forest site included as random variable. Pairwise differences for abundance and species density for which host tree species revealed significance, were separated using a Tukey post-hoc test using the emmeans package in $\mathrm{R}^{63}$.

At the small spatial scale, analyses of arthropod assemblage composition can be a more sensitive tool than analyses of species density and abundance data alone ${ }^{66}$. To determine differences in arthropod assemblages between selected tree species, we conducted permutational multivariate analysis of variance (PERMANOVA) in the programme PRIMER $6^{64}$, on square-root transformed data, using Bray-Curtis similarity matrices. These results were visualised using Canonical Analysis of Principal coordinates (CAP) in the same programme. The respective effects of the different variables mentioned above on arthropod assemblage composition were determined using distance-based linear modelling (DistLM) of Bray-Curtis similarity matrices, using specified selection in PRIMER 6. This method allows for the addition of variables to the analyses based on their total variation explained, until no further variables improved the model based on $\mathrm{AICc}^{67}$.

Effect of intraspecific physiological variation on arthropod diversity. To test the extent to which a tree's physiological features explained variation in arthropod species density and abundance for each of the arthropod groups, several candidate models were evaluated for each tree species separately. The full model included the variables $\mathrm{N}, \mathrm{C}, \delta 15 \mathrm{~N} / 14 \mathrm{~N}, \delta 13 \mathrm{C} / 12 \mathrm{C}$ and $\mathrm{C} / \mathrm{N}$, with forest site included as random variable, and response variable being either abundance or species density for each arthropod guild. The candidate models for each guild totalled 32 , with each model containing a unique combination of variables. Relative support for the models was then determined using the AICc criterion with best model selection using the package AICcmodavg in R, after which Generalised Linear Mixed Models (GLMMs) with poisson distributions were constructed using the candidate model with lowest AICc. To explain variation in arthropod assemblage composition as described by the five plant physiological characteristics, distance-based linear modelling (DistLM) was performed for each arthropod guild, on each tree species, based on Bray-Curtis similarity matrices, using specified selection in PRIMER $6^{64}$.

Received: 11 May 2020; Accepted: 2 November 2020

Published online: 16 November 2020

\section{References}

1. Nakamura, A. et al. Forests and their canopies: achievements and horizons in canopy science. Trends Ecol. Evol. 32, 438-451 (2017).

2. Wardhaugh, C. W., Stork, N. E. \& Edwards, W. Feeding guild structure of beetles on Australian tropical rainforest trees reflects microhabitat resource availability. J. Anim. Ecol. 81, 1086-1094 (2012).

3. Arias, E. T., Richardson, B. J. \& Elgueta, M. The canopy beetle faunas of Gondwanan element trees in Chilean temperate rain forests. J. Biogeogr. 35, 914-925 (2008).

4. Tovar-Sánchez, E., Valencia-Cuevas, L., Mussali-Galante, P., Ramírez-Rodríguez, R. \& Castillo-Mendoza, E. Effect of host-plant genetic diversity on oak canopy arthropod community structure in central Mexico. Rev. Chil. Hist. Nat. 88, 12 (2015).

5. Allison, A., Samuelson, G. A. \& Miller, S. E. Patterns of beetle species diversity in Castanopsis acuminatissima (Fagaceae) trees studied with canopy fogging in mid-montane New Guinea rainforest. In Canopy Arthropods (eds Stork, N. E. et al.) 224-236 (Chapman \& Hall, London, 1997).

6. Basset, Y. \& Arthington, A. H. The arthropod community of an Australian rainforest tree: abundance of component taxa, species richness and guild structure. Austral. Ecol. 17, 89-98 (1992).

7. Stork, N. E., Hammond, P. M., Russell, B. L. \& Hadwen, W. L. The spatial distribution of beetles within the canopies of oak trees in Richmond Park UK. Ecol. Entomol. 26, 302-311 (2001).

8. Yekwayo, I., Pryke, J. S., Gaigher, R. \& Samways, M. J. Only multi-taxon studies show the full range of arthropod responses to fire. PLOS ONE 13, e0195414 (2018).

9. Wardhaugh, C. W., Edwards, W. \& Stork, N. E. The specialization and structure of antagonistic and mutualistic networks of beetles on rainforest canopy trees. Biol. J. Linn. Soc. 114, 287-295 (2015).

10. Wardhaugh, C. W. The spatial and temporal distributions of arthropods in forest canopies: uniting disparate patterns with hypotheses for specialisation. Biol. Rev. 89, 1021-1041 (2014).

11. Swart, R. C., Samways, M. J., Pryke, J. S. \& Roets, F. Individual tree context and contrast dictate tree physiological features and arthropod biodiversity patterns across multiple trophic levels. Ecol. Entomol. 45, 333-344 (2020).

12. Knapp, A. K. \& Smith, W. K. Stomatal and photosynthetic responses to variable sunlight. Physiol. Plant. 78, 160-165 (1990).

13. Pollastrini, M. et al. Growth and physiological responses to ozone and mild drought stress of tree species with different ecological requirements. Trees 24, 695-704 (2010).

14. Maoela, M. A., Esler, K. J., Roets, F. \& Jacobs, S. M. Physiological responses to folivory and phytopathogens in a riparian tree, Brabejum stellatifolium, native to the fynbos biome of South Africa. Afr. J. Ecol. 56, 477-487 (2018).

15. Gely, C., Laurance, S. G. \& Stork, N. E. How do herbivorous insects respond to drought stress in trees?. Biol. Rev. 95, 434-448 (2020).

16. Allen, C. D. et al. A global overview of drought and heat-induced tree mortality reveals emerging climate change risks for forests. For. Ecol. Manag. 259, 660-684 (2010).

17. Scholze, M., Knorr, W., Arnell, N. W. \& Prentice, I. C. A climate-change risk analysis for world ecosystems. PNAS 103, 13116-13120 (2006).

18. Forrest, J. R. Plant-pollinator interactions and phenological change: what can we learn about climate impacts from experiments and observations?. Oikos 124, 4-13 (2015). 
19. Hosseini, M., Karimi, J., Madadi, H., Hosseini, A. \& Goldani, M. Effect of nitrogen fertilizer on biological parameters of the Aphis craccivora (Hemiptera: Aphidiae) and associated productivity losses in common globe amaranth. JAST 17, 1517-1528 (2018).

20. Chacón, P. \& Armesto, J. J. Do carbon-based defences reduce foliar damage? Habitat-related effects on tree seedling performance in a temperate rainforest of Chiloé Island Chile. Oecologia 146, 555-565 (2006).

21. Barber, N. A. \& Marquis, R. J. Light environment and the impacts of foliage quality on herbivorous insect attack and bird predation. Oecologia 166, 401-409 (2011).

22. Akula, R. \& Ravishankar, G. A. Influence of abiotic stress signals on secondary metabolites in plants. Plant Signal. Behav. 6, $1720-1731$ (2011).

23. Walker, X. J., Mack, M. C. \& Johnstone, J. F. Stable carbon isotope analysis reveals widespread drought stress in boreal black spruce forests. Glob. Chang. Biol. 21, 3102-3113 (2015).

24. Craine, J. M. et al. Ecological interpretations of nitrogen isotope ratios of terrestrial plants and soils. Plant Soil. 396, 1-26 (2015).

25. Dial, R. J., Ellwood, M. D., Turner, E. C. \& Foster, W. A. Arthropod abundance, canopy structure, and microclimate in a Bornean lowland tropical rain forest. Biotropica 38, 643-652 (2006).

26. Darwin, C. On the origin of species (John Murray, London, 1859).

27. Wardhaugh, C. W., Stork, N. E. \& Edwards, W. Specialization of rainforest canopy beetles to host trees and microhabitats: not all specialists are leaf-feeding herbivores. Biol. J. Linn. Soc. 109, 215-228 (2013).

28. Esquivel-Gómez, L., Abdala-Roberts, L., Pinkus-Rendón, M. \& Parra-Tabla, V. Effects of tree species diversity on a community of weaver spiders in a tropical forest plantation. Biotropica 49, 63-70 (2017).

29. Root, R. B. Organization of a plant-arthropod association in simple and diverse habitats: the fauna of collards (Brassica oleracea). Ecol. Monogr. 43, 95-124 (1973).

30. Muiruri, E. W. et al. Forest diversity effects on insect herbivores: do leaf traits matter?. New Phytol. 221, 2250-2260 (2019).

31. Mole, S., Ross, J. A. \& Waterman, P. G. Light-induced variation in phenolic levels in foliage of rain-forest plants. J. Chem. Ecol 14, $1-21(1988)$.

32. Pérez-López, U. et al. Concentration of phenolic compounds is increased in lettuce grown under high light intensity and elevated $\mathrm{CO}_{2}$. Plant Physiol. Biochem. 123, 233-241 (2018).

33. Jeffries, J. M., Marquis, R. J. \& Forkner, R. E. Forest age influences oak insect herbivore community structure, richness, and density. Ecol. Appl. 16, 901-912 (2006).

34. Sipura, M. \& Tahvanainen, J. Shading enhances the quality of willow leaves to leaf beetles-but does it matter?. Oikos 91, 550-558 (2000).

35. Sweaney, N., Driscoll, D. A., Lindenmayer, D. B. \& Porch, N. Plantations, not farmlands, cause biotic homogenisation of groundactive beetles in south-eastern Australia. Biol. Conserv. 186, 1-11 (2015).

36. Jongman, R. H. Homogenisation and fragmentation of the European landscape: ecological consequences and solutions. Landsc. Urban. Plan. 58, 211-221 (2002).

37. Russell, E. P. Enemies hypothesis: a review of the effect of vegetational diversity on predatory insects and parasitoids. Environ. Entomol. 18, 590-599 (1989).

38. Nelson, C. D. \& Johnsen, K. H. Genomic and physiological approaches to advancing forest tree improvement. Tree Physiol. 28, 1135-1143 (2008).

39. Lloyd, A. H. \& Bunn, A. G. Responses of the circumpolar boreal forest to 20th century climate variability. Environ. Res. Lett. 2, 045013 (2007).

40. McGroddy, M. E., Daufresne, T. \& Hedin, L. O. Scaling of C: N: P stoichiometry in forests worldwide: Implications of terrestrial redfield-type ratios. Ecology 85, 2390-2401 (2004).

41. Walker, A. P. et al. Predicting long-term carbon sequestration in response to $\mathrm{CO}_{2}$ enrichment: how and why do current ecosystem models differ?. Glob. Biogeochem. Cycles 29, 476-495 (2015).

42. Dury, S. J., Good, J. E. G., Perrins, C. M., Buse, A. \& Kaye, T. The effects of increasing $\mathrm{CO}_{2}$ and temperature on oak leaf palatability and the implications for herbivorous insects. Glob. Change Biol. 4, 55-61 (1998).

43. Hall, M. C., Stiling, P., Moon, D. C., Drake, B. G. \& Hunter, M. D. Effects of elevated $\mathrm{CO}_{2}$ on foliar quality and herbivore damage in a scrub oak ecosystem. J. Chem. Ecol. 31, 267-286 (2005).

44. Cornelissen, T. Climate change and its effects on terrestrial insects and herbivory patterns. Neotrop. Entomol. 40, 155-163 (2011).

45. Hunter, M. D. Effects of elevated atmospheric carbon dioxide on insect-plant interactions. Agric. For. Entomol. 3, 153-159 (2001).

46. Williams, R. S., Lincoln, D. E. \& Thomas, R. B. Loblolly pine grown under elevated $\mathrm{CO}_{2}$ affects early instar pine sawfly performance. Oecologia 98, 64-71 (1994).

47. Lindroth, R. L., Jung, S. M. \& Feuker, A. M. Detoxication activity in the gypsy moth: effects of host $\mathrm{CO}_{2}$ and $\mathrm{NO}_{3}^{-}$availability. J. Chem. Ecol. 19, 357-367 (1993).

48. Hellmann, J. J., Prior, K. M. \& Pelini, S. L. The influence of species interactions on geographic range change under climate change. Ann. N. Y. Acad. Sci. 1249, 18-28 (2012).

49. Brearley, F. Q., Press, M. C. \& Scholes, J. D. Nutrients obtained from leaf litter can improve the growth of dipterocarp seedlings. New Phytol. 160, 101-110 (2003).

50. Aerts, R. Interspecific competition in natural plant communities: mechanisms, trade-offs and plant-soil feedbacks. J. Exp. Bot. 50, 29-37 (1999).

51. García-Plazaola, J. I., Esteban, R., Hormaetxe, K., Fernández-Marín, B. \& Becerril, J. M. Photoprotective responses of Mediterranean and Atlantic trees to the extreme heat-wave of summer 2003 in Southwestern Europe. Trees 22, 385-392 (2008).

52. Geldenhuys, C. J. Floristic composition of the southern Cape forests with an annotated check-list. S. Afr. J. Bot. 59, 26-44 (1993).

53. Proçhes, Ş \& Cowling, R. M. Insect diversity in Cape fynbos and neighbouring South African vegetation. Glob. Ecol. Biogeogr. 15, 445-451 (2006).

54. Nakamura, M., Inari, N. \& Hiura, T. Spatial variation in leaf traits and herbivore community within the beech canopy between two different latitudes. Arthropod-Plant Interact. 8, 571-579 (2014).

55. Scholtz, C. H. \& Holm, E. Insects of Southern Africa (Protea Book House, Pretoria, 1985).

56. Labandeira, C. C. Insect mouthparts: ascertaining the paleobiology of insect feeding strategies. Annu. Rev. Ecol. Evol. Syst. 28, $153-193$ (1997).

57. Moran, V. C. \& Southwood, T. R. E. The guild composition of arthropod communities in trees. J. Anim. Ecol. 15, 289-306 (1982).

58. Stork, N. E. Guild structure of arthropods from Bornean rain forest trees. Ecol. Entomol. 12, 69-80 (1987).

59. Samways, M. J., McGeoch, M. A. \& New, T. R. Insect Conservation: A Handbook of Approaches and Methods (Oxford University Press, Oxford, 2010).

60. Peterson, R. A. \& Cavanaugh, J. E. Ordered quantile normalization: a semiparametric transformation built for the cross-validation era. J. Appl. Stat. 46, 1-16 (2019).

61. Bates, D., Sarkar, D., Bates, M. D. \& Matrix, L. The lme4 package. R Package Version 2, 74 (2007).

62. Bolker, B. M. et al. Generalized linear mixed models: a practical guide for ecology and evolution. Trends Ecol. Evol. 24, 127-135 (2009).

63. Magnusson, A. et al. Package 'glmmTMB'. R Package Version 0.2.0 (2017).

64. Clarke, K. R. \& Gorley, R. N. Primer. PRIMER-e (Plymouth 2006)

65. Brooks, M. E. et al. Modeling zero-inflated count data with glmmTMB. BioRxiv, 132753 (2017). 
66. Stork, N. E. et al. Consistency of effects of tropical-forest disturbance on species composition and richness relative to use of indicator taxa. Conserv. Biol. 31, 924-933 (2017).

67. Burnham, K. P. \& Anderson, D. R. Multimodel inference: understanding AIC and BIC in model selection. Sociol. Methods Res. 33, 261-304 (2004).

\section{Acknowledgements}

We thank A. Cilliers for assistance in the field. Thanks also to SANParks (Garden Route National Park, Scientific Services: N. Kruger, M. de Mornay, J. Baard, W. Vermeulen, G. Durrheim, G. Sass), Cape Nature (Grootvadersbosch Nature Reserve: I. Allen, L. Michaels), Mosselbay Municipality (C. Schutte), and landowners at Oubos (M. Willemse, S. Beyers) for permission to sample, as well as Dyna Fog Africa (especially D. Bird) for their support. Funding was from the National Research Foundation (grant number SFH150723130214). We also sincerely thank A. Dippenaar-Schoeman and C. Haddad for help with spider identifications, and M. de Mornay for help with ant identifications.

\section{Author contributions}

R.C.S. Study design, data collection, laboratory work, statistical analyses, writing of first draft; M.J.S. Study concept, acquired funding, writing of manuscript; F.R. Study concept, acquired funding, writing of manuscript.

\section{Competing interests}

The authors declare no competing interests.

\section{Additional information}

Supplementary information is available for this paper at https://doi.org/10.1038/s41598-020-76868-8.

Correspondence and requests for materials should be addressed to R.C.S.

Reprints and permissions information is available at www.nature.com/reprints.

Publisher's note Springer Nature remains neutral with regard to jurisdictional claims in published maps and institutional affiliations.

(c) (i) Open Access This article is licensed under a Creative Commons Attribution 4.0 International License, which permits use, sharing, adaptation, distribution and reproduction in any medium or format, as long as you give appropriate credit to the original author(s) and the source, provide a link to the Creative Commons licence, and indicate if changes were made. The images or other third party material in this article are included in the article's Creative Commons licence, unless indicated otherwise in a credit line to the material. If material is not included in the article's Creative Commons licence and your intended use is not permitted by statutory regulation or exceeds the permitted use, you will need to obtain permission directly from the copyright holder. To view a copy of this licence, visit http://creativecommons.org/licenses/by/4.0/.

(c) The Author(s) 2020 